\title{
NOT ANOTHER CANCER JOURNAL!
}

Do we really need another cancer journal in the already crowded world of oncology literature? That was the first thought that crossed my mind when Drs. Aasim Yusuf and Humayun Bashir invited me to work with them on this nascent effort. However, to my surprise, the answer was a resounding 'yes!' after they walked me through their vision. There is a paucity of oncology publications with a true multidisciplinary flavour dealing with pathophysiology in this region with its huge disparities not only in ethnicity but also in availability of resources to tackle their complex cancer-related issues. Working out of Shaukat Khanum Memorial Cancer Hospital and Research Centre (SKMCHRC), Pakistan's premier institution for cancer treatment and research, Dr. Bashir, with Dr. Yusuf's support and patronage has been able to assemble a truly international group of cancer experts to supplement their own impressive list of faculty on the editorial board. They have been able to get quality manuscripts for this inaugural issue and intend to publish two issues this year, three the next, and make it quarterly thereafter.

The content of this first issue includes three research articles, one review article, three case reports and four images in oncology. The content will remain diverse and varied, and will include the meritorious research presented at the annual cancer conference of the SKMCHRC. Submissions from outside, particularly from international faculty, will be encouraged. We welcome your feedback to continuously evolve our content to suit the needs of our readership.

This project would not have come to fruition without the help and expertise of a large number of individuals from the SKMCHRC team. A special thanks to Mr. Manzar Abbas and Ms. Bushra Sajjad for helping in the webpage design; and to the paediatric surgeons, Dr. Abid Qazi at SKMHRC and Dr. Bilal Mirza at the Children's Hospital, Lahore, for their help with the online launch. We are also indebted to Mr. Tazeen Qureshi in the Marketing Department who worked on the publishing layout and design. Dr. Waleed Zafar should be thanked for checking syntax and language of all manuscripts.

I am really honoured to work with such a talented team and our international editorial board. We will be thanking our reviewers and listing their names annually on our website, at the end of the year. I commend the efforts of Dr. Humayun Bashir, as this publication would not have been possible without his tireless efforts and organisational skills, which were well recognised and supported by Dr. Aasim Yusuf.

In the coming weeks and months, we will be looking forward to your feedback, as well as your submissions to this peer-reviewed journal. We believe this publication will promote original research in the region and improve the care of cancer patients by disseminating evidencebased information relevant to their care. The journey has just begun!

Mohammad Jahanzeb

Department of Clinical Medicine, HematologyOncology Sylvester Comprehensive Cancer Center, Deerfield Beach Campus, University of Miami Miller School of Medicine, Miami, Florida, United States Received: 4 April 2015 / Accepted: 23 April 2015 